\title{
Prediksi Pemakaian Listrik Kelompok Tarif Menggunakan Jaringan Syaraf Tiruan dan ARIMA
}

(Studi Kasus Wilayah Suluttenggo)

\author{
Silviani E Rumagit*1 dan Azhari $\mathrm{SN}^{2}$ \\ ${ }^{1}$ Mahasiswa Program Pascasarjana Ilmu Komputer, FMIPA, UGM, Yogyakarta. \\ ${ }^{2}$ Staf Pengajar Program Pascasarjana Ilmu Komputer, FMIPA UGM, Yogyakarta \\ e-mail: *11 silviani_rumagit@mail.ugm.ac.id, ${ }^{2}$ arisn@ugm.ac.id
}

\begin{abstract}
Abstrak
Latar Belakang penelitian ini dibuat dimana semakin meningkatnya kebutuhan listrik di setiap kelompok tarif. Yang dimaksud dengan kelompok tarif dalam penelitian ini adalah kelompok tarif sosial, kelompok tarif rumah tangga, kelompok tarif bisnis, kelompok tarif industri dan kelompok tarif pemerintah. Prediksi merupakan kebutuhan penting bagi penyedia tenaga listrik dalam mengambil keputusan berkaitan dengan ketersediaan energi listik. Dalam melakukan prediksi dapat dilakukan dengan metode statistik maupun kecerdasan buatan.

ARIMA merupakan salah satu metode statistik yang banyak digunakan untuk prediksi dimana ARIMA mengikuti model autoregressive (AR) moving average (MA). Syarat dari ARIMA adalah data harus stasioner, data yang tidak stasioner harus distasionerkan dengan differencing. Selain metode statistik, prediksi juga dapat dilakukan dengan teknik kecerdasan buatan, dimana dalam penelitian ini jaringan syaraf tiruan backpropagation dipilih untuk melakukan prediksi. Dari hasil pengujian yang dilakukan selisih MSE ARIMA, JST dan penggabungan ARIMA, jaringan syaraf tiruan tidak berbeda secara signifikan.
\end{abstract}

Kata Kunci-ARIMA, jaringan syaraf tiruan, kelompok tarif.

\begin{abstract}
Background this research was made where the increasing demand for electricity in each group. The meaning this group is social, the household, business, industry groups and the government fare. Prediction is an important requirement for electricity providers in making decisions related to the availability of electric energy. In doing predictions can be made by statistical methods and artificial intelligence.

ARIMA is a statistical method that is widely used to predict where the ARIMA modeled autoregressive (AR) moving average (MA). Terms of ARIMA is the data must be stationary, the data is not stationary should be stationary use differencing. In addition to the statistical method, predictions can also be done by artificial intelligence techniques, which in this study selected Backpropagation neural network to predict. From the results of tests made the difference in MSE ARIMA, ANN and merging ARIMA, artificial neural networks are not significantly different.
\end{abstract}

Keyword-ARIMA, neural network, tarif groups

Received June $1^{\text {st }}$ 2013; Revised July $1^{\text {st }}$, 2013; Accepted July 15 ${ }^{\text {th }}, 2013$ 


\section{PENDAHULUAN}

$\mathrm{T}$ enaga listrik merupakan kebutuhan pokok bagi masyarakat. Tenaga listrik digunakan oleh beberapa sektor, antara lain sektor rumah tangga, industri, usaha komersial, dan tempat layanan umum. Tenaga Listrik tidak dapat disimpan dalam skala besar, karenanya tenaga ini harus disediakan pada saat dibutuhkan. Akibatnya timbul persoalan dalam menghadapi kebutuhan daya listrik yang tidak tetap dari waktu ke waktu. Akibatnya timbul persoalan dalam menghadapi kebutuhan daya listrik yang tidak tetap dari waktu ke waktu, bagaimana mengoperasikan suatu sistem tenaga listrik yang selalu dapat memenuhi permintaan daya pada setiap saat. Prediksi kelistrikan merupakan salah satu bidang yang banyak diteliti karena listrik merupakan salah satu jenis energi utama, sehingga diperlukan perencanaan yang baik untuk mengetahui permintaan listrik di masa [1]. Tenaga listrik tidak dapat disimpan dalam skala besar, karenanya tenaga ini harus disediakan pada saat dibutuhkan sehingga secara langsung mempengaruhi biaya untuk pengoperasian dan pembangunan tenaga listrik[2].

Salah satu model yang dapat digunakan untuk memprediksi besar konsumsi listrik adalah dengan analisis time series. Prediksi time series merupakan metode kuantitatif yang banyak dikembangkan saat ini dimana hal tersebut dapat dibagi menjadi dua bagian yaitu pertama, prediksi didasarkan pada model matematika tradisional seperti ARIMA, model regresi nonparametik, dll. Kedua, model prediksi yang tidak memperhatikan derivasi matematika secara ketat seperti jaringan syaraf tiruan, analisis secara spectral, dll [3].

Alasan untuk melakukan pengkombinasian model ARIMA dan jaringan syaraf tiruan. Pertama, sering kali terjadi kesulitan untuk menerapkan penggunaan model linear atau model nonlinear pada suatu permasalahan time series. Kedua, pada kenyataannya time series jarang yang linear atau nonlinear saja tetapi sering mengandung keduanya, dimana tidak hanya model ARIMA atau jaringan syaraf masing-masing dapat memodelkan setiap kasusnya [4]. Rahayu [5], yang meneliti sistem peramalan beban listrik menggunakan jaringan syaraf tiruan untuk wilayah Sumetera Selatan dan Lampung. Faisal dan Rizal [6], menggunakan metode ARIMA untuk melakukan simulasi dan menganalisis data untuk mendapatkan model matematika pemakaian $\mathrm{kWh}$ listrik pelanggan untuk mendapatkan model matematika pemakaian $\mathrm{kWh}$ listrik pelanggan.

Metode ARIMA merupakan salah satu metode yang banyak digunakan untuk melakukan prediksi time series yang biasa dikenal juga dengan metode Box-Jenkins [7]. Syarat dari ARIMA data harus stasioner terlebih dahulu sebelum dilakukan prediksi, jika data tidak stasioner dilakukan difference $[8,9]$. Data masa lampau dikumpulkan, dipelajari dan dianalisa dihubungkan dengan geraknya waktu. Karena adanya faktor waktu ini, maka dari hasil analisa tersebut dicoba diprediksi apa yang akan terjadi dimasa mendatang [10].

\section{METODE PENELITIAN}

Penelitian mengambil kasus pemakaian listrik kelompok tarif di wilayah PLN Suluttenggo, data yang digunakan adalah data pemakaian listrik bulan Januari 2004 sampai dengan bulan Desember 2010. Data bulan Januari 2004 sampai bulan Februari 2008 dijadikan sebagai data in sample untuk pembuatan ARIMA dan data bulan Maret 2008 sampai bulan Desember 2010 digunakan sebagai data out sample. Input dari sistem adalah data pemakaian listrik per kelompok tarif, sedangkan output sistem adalah pemakaian listrik untuk enam periode berikutnya. Metode yang akan digunakan adalah ARIMA, jaringan syaraf tiruan feedforward dengan pelatihan Backpropagation, dan gabungan dari ARIMA dan JST. Prediksi dilakukan pada masing-masing kelompok tarif yang terbagi dalam lima kelompok tarif yaitu: kelompok tarif sosial, rumah tangga, bisnis, industri dan pemerintah. Metode yang akan digunakan adalah ARIMA, jaringan syaraf tiruan feedforward dengan pelatihan backpropagation, dan gabungan dari ARIMA dan JST. Pada table1 menunjukkan data yang akan digunakan dalam penelitian ini.

IJCCS Vol. 7, No. 2, July 2013 : $189-198$ 
Tabel . Data pemakaian listrik

\begin{tabular}{|c|c|l|r|l|l|r|}
\hline No & bln/thn & Sosial & $\begin{array}{l}\text { Rumah } \\
\text { Tangga }\end{array}$ & Bisnis & Industri & Pemerintah \\
\hline 1 & Jan04 & 3031617 & 48728562 & 11535459 & 6467504 & 5292898 \\
\hline 2 & Feb04 & 2989570 & 48693099 & 12119528 & 6981198 & 5280052 \\
\hline 3 & Mar04 & 2947089 & 47404875 & 12170612 & 7124098 & 5309385 \\
\hline 4 & Apr04 & 3121971 & 48560363 & 11950558 & 7139702 & 5916665 \\
\hline 5 & Mei04 & 3092962 & 49474183 & 12883808 & 8081441 & 5868457 \\
\hline. &. &. &. &. &. &. \\
\hline. &. &. &. &. &. &. \\
\hline. &. &. &. &. &. &. \\
\hline 81 & Sept10 & 5325729 & 81355067 & 25604721 & 7681332 & 10117575 \\
\hline 82 & Okt10 & 5304754 & 87898018 & 28229820 & 8087973 & 10063356 \\
\hline 83 & Nov10 & 5724876 & 86713749.67 & 28002804 & 8648356 & 11056674 \\
\hline 84 & Des10 & 6037107 & 97106902 & 27488599 & 8253485 & 10967248 \\
\hline
\end{tabular}

Model Autoregressive Integrated Moving Average (ARIMA) merupakan pendekatan model kuantitatif yang dikembangkan oleh George Box dan Gwilym Jenkins tahun 1976 dimana metode ini memanfaatkan data masa lalu dan data sekarang untuk menghasilkan prediksi yang akurat [9].

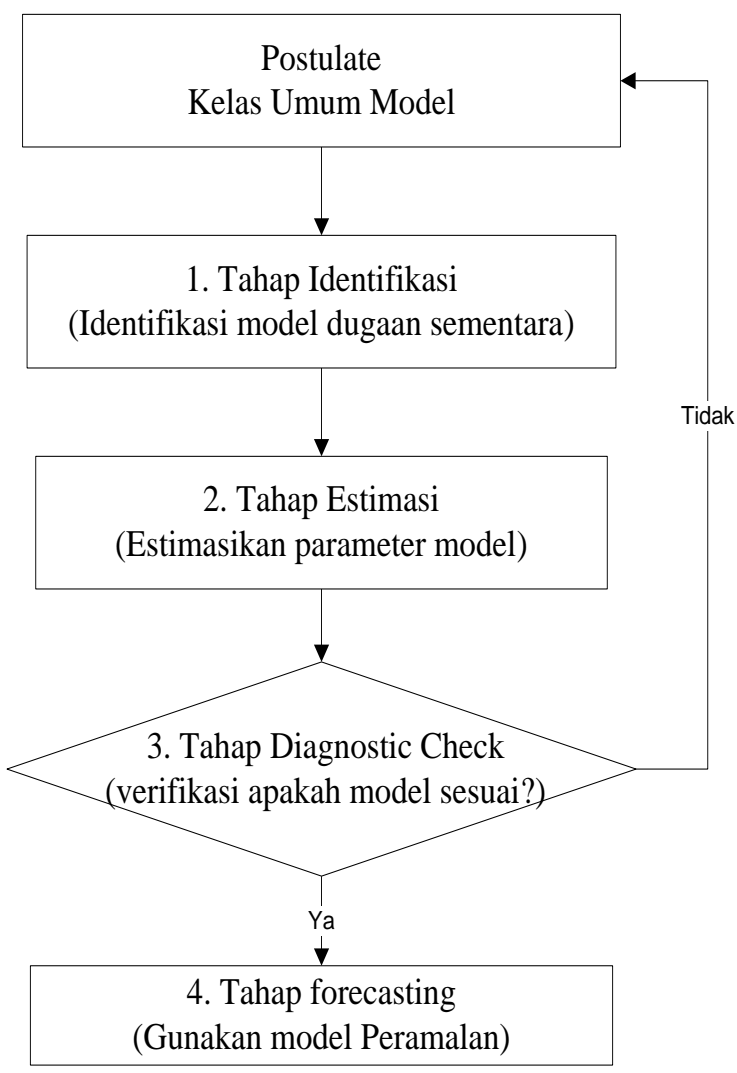

Gambar 1. Tahapan pembangunan ARIMA 
ARIMA merupakan model gabungan dari autoregressive (AR) dan moving average (MA) yang dideference. Banyaknya nilai lampai yang digunakan pada model (p) menunjukkan tingkat dari model itu. Jika hanya digunakan satu nilai lampau, maka itu model AR tingkat satu dan dilambangkan dengan AR (1). Model autoregressive orde $\mathrm{p}$ atau AR (p), rumus umumnya sebagai berikut:

$$
Y_{\mathrm{t}}=B_{1} Y_{\mathrm{t}-1}+B_{2} Y_{\mathrm{t}-2}+\cdots+B_{p} Y_{\mathrm{t}-\mathrm{p}}+e_{\mathrm{t}}
$$

Keterangan:

$Y_{t} \quad=$ variabel dependen

$Y_{t-1,}, Y_{t-2,}, Y_{t-p,}=$ variabel independent atau nilai lampau variabel yang bersangkutan

$B_{1}, B_{2}, B_{p} \quad=$ koefisien regresi

$e_{t} \quad=$ nilai residual atau error pada periode $\mathrm{t}$

Rumus umum model moving average orde q atau MA (q) sebagai berikut:

$$
Y_{t}=e_{t}-W_{1} e_{t-1}-W_{2} e_{t-2}-\cdots-W_{q} e_{t-q}
$$

$Y_{t} \quad=$ variabel dependent

$W_{1}, W_{2}, W_{q} \quad=$ bobot

$e_{t} \quad=$ residual atau error

$e_{t-1,}, e_{t-2,} e_{t-p} \quad=\mathrm{n}$ ilai residual sebelumnya

Perbedaan model moving average dengan model autoregressive terletak pada jenis variabel independen. Bila variabel independen pada model autoregressive adalah nilai sebelumnya (lag) dari variabel dependen $\left(\mathrm{Y}_{\mathrm{t}}\right)$ itu sendiri, maka pada model moving average sebagai variabel independennya adalah nilai residual pada periode sebelumnya. Banyaknya kesalahan yang digunakan pada persamaan ini menandai tingkat dari model moving average

Model umum dari ARIMA (p,q) adalah kombinasi dari persamaan AR dan MA yang membentuk rumus seperti berikut:

$\mathrm{Yt}=B_{1} Y_{t-1}+B_{2} Y_{t-2}+\cdots+B_{p} Y_{t-p}+e_{t}-W_{1} e_{t-1}-W_{2} e_{t-2}-\cdots-W_{q} e_{t-q}$

Alat utama utama yang digunakan untuk mengidentifikasi q dan $\mathrm{p}$ adalah ACF dan PACF dan correlogram yang menunjukkan plot nilai ACF dan PACF terhadap lag. Koefisien autokolerasi merupakan kunci untuk analisis deret berkala sehingga autokorelasi (ACF) untuk time lag $k$ dapat dicari dengan:

$$
r_{k}=\frac{\sum_{t=1}^{n-k}\left(\mathrm{y}_{\mathrm{t}}-\overline{\mathbf{y}}\right)\left(\mathrm{y}_{\mathrm{t}+\mathrm{k}}-\overline{\mathbf{Y}}\right)}{\mathrm{s}_{\mathrm{t}-1}^{\mathrm{n}}\left(\mathrm{v}_{\mathrm{t}}-\overline{\mathbf{y}}\right)^{2}}
$$

dimana:

$r_{k}=$ nilai ACF pada lag $k$

$\mathrm{k}=$ waktu periode time series

$\mathrm{Y}_{\mathrm{t}}=$ nilai deret berkala pada waktu $\mathrm{t}$

$\overline{\mathrm{Y}}=$ nilai tengah (mean) dari deret berkala

$\mathrm{n}=$ jumlah dari observasi

Jika $n_{k}=0$ maka $\mathrm{Y}_{\mathrm{t}+\mathrm{k}}$ dan $\mathrm{Y}_{\mathrm{t}}$ data yang ada tidak berkorelasi

ACF mengukur korelasi antar pengamatan dengan jeda $\mathrm{k}$, sedangkan PACF mengukur korelasi antar pengamatan dengan jeda $\mathrm{k}$ dan dengan mengontrol korelasi antar dua pengamatan dengan jeda kurang dari $\mathrm{k}$. PACF adalah korelasi antara $\mathrm{Y}_{\mathrm{t}}$ yang terletak diantara kedua pengamatan.

$$
P_{k}=\frac{r_{k}-\Sigma_{\mathrm{j}=1}^{\mathrm{k}-1} P_{k-1, j} r_{k-1}}{1-\Sigma_{\mathrm{j}=1}^{\mathrm{k}-1} P_{k-1, j} r_{j}}
$$

dimana: 


$$
\begin{aligned}
& P_{k}=\text { nilai } \mathrm{PACF} \text { dengan ordo } \mathrm{k} \\
& r_{k}=\text { nilai ACF pada lag } \mathrm{k}
\end{aligned}
$$

Tahapan prediksi model ARIMA antara lain:

1. Tahap Identifikasi

Langkah pertama dalam identifikasi model adalah menentukan deret berkala stasioner.

Identifikasi diawali dengan membuat plot data.

2. Tahap Estimasi

Setelah bentuk model yang kira-kira sesuai untuk data ditentukan, selanjutnya mengestimasi parameter dalam model, seperti koefisien dari model ARMA dan nilai variansi dari residual.

3. Tahap Diagnostik Model

Langkah selanjutnya adalah melakukan cek diagnostik dari model yang telah di estimasi di langkah 2, yakni memverifikasi kesesuaian model dengan sifat-sifat data. Jika model merupakan model yang tepat, data yang dihitung dengan model akan memiliki sifatsifat yang mirip dengan data asli. Untuk memilih model terbaik, pilih model yang meminimalkan MSE.

4. Tahap Forecasting

Setelah model terbaik diperoleh dari langkah-langkah pemodelan di atas, model tersebut dapat digunakan untuk meramalkan sifat-sifat data di masa yang akan mendatang. Beberapa ukuran kebaikan penyesuaian atau peramalan dapat digunakan ukuran MSE.

Jaringan syaraf tiruan didefinisikan sebagai suatu sistem pemrosesan infomasi yang mempunyai karakteristik menyerupai jaringan syaraf manusia. Jaringan syaraf tiruan tercipta sebagai suatu generalisasi model matematis dari pemahaman manusia (human cognition) yang didasarkan atas asumsi sebagai berikut:

1. Pemrosesan informasi terjadi pada elemen sederhana yang disebut neuron.

2. Sinyal mengalir di antara sel syaraf/neuron melalui suatu sambungan penghubung.

3. Setiap sambungan penghubung memiliki bobot yang bersesuaian. Bobot ini akan digunakan untuk menggandakan atau mengalikan isyarat yang dikirim melaluinya.

Setiap sel syaraf akan menerapkan fungsi aktivasi terhadap isyarat hasil penjumlahan berbobot yang masuk kepadanya untuk menentukan isyarat keluarannya [11]. Model jaringan syaraf tiruan feedforward multilayer digunakan dalam aplikasi prediksi yang akan dibuat. Langkah pertama adalah menentukan parameter-parameter yang akan digunakan dalam melatih jaringan syaraf pada data times series. Adapun langkah-langkah penentuan paremeter adalah:

1. Menentukan arsitektur jaringan.

Arsitektur jaringan yang dibuat terdiri dari tiga lapisan yang tersusun dari 1 lapisan input, 1 lapisan tersembunyi, dan 1 lapisan output.

2. Fungsi Aktivasi.

Fungsi-fungsi aktivasi yang akan digunakan untuk semua unit-unit tersembunyi adalah fungsi sigmoid biner dan untuk lapisan output digunakan fungsi sigmoid bipolar.

3. Algoritma Pelatihan.

Metode yang digunakan untuk pembelajaran adalah algoritma backpropagation.

4. Bobot awal dan bias awal jaringan ditetapkan secara random.

5. Maksimum epochs.

Maksimum epoch adalah jumlah epoch maksimum yang boleh dilakukan selama proses training. Iterasi akan dihentikan jika nilai epoch telah melebihi epoch yang telah ditentukan yaitu1000 epoch.

Pada penelitian ini ditentukan 6 neuron input, 20 neuron hidden layer dan 1 output seperti pada Gambar 2. 


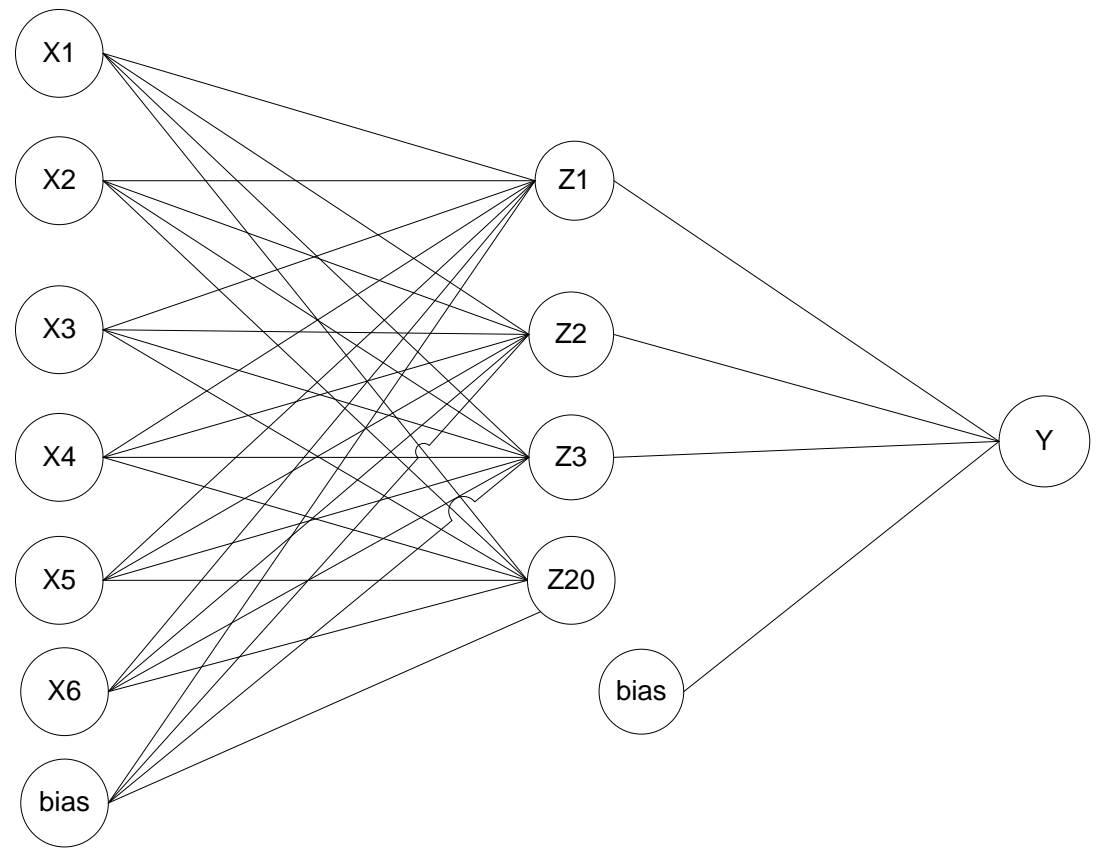

Gambar 2 Arsitektur jaringan

Model ARIMA dan JST merupakan kombinasi dari dua model menjadi satu. Pemodelan dilakukan di ARIMA kemudian dari model yang memiliki minimum MSE dipilih menjadi input untuk JST yang terbagi dalam 3 input yaitu:

1. Input pada lag-1 $\left(\mathrm{Y}_{\mathrm{t}-1}\right)$,

2. Input pada lag-1 $\left(\mathrm{Y}_{\mathrm{t}-1}\right)$, dan lag-2,

3. Input pada lag-1 $\left(\mathrm{Y}_{\mathrm{t}-1}\right)$, lag-2 $\left(\mathrm{Y}_{\mathrm{t}-2}\right)$, lag-3 $\left(\mathrm{Y}_{\mathrm{t}-\mathrm{3}}\right)$, lag-4 $\left(\mathrm{Y}_{\mathrm{t}-4}\right)$, lag-5 $\left(\mathrm{Y}_{\mathrm{t}-5}\right)$, lag-6 $\left(\mathrm{Y}_{\mathrm{t}-6}\right)$.

Pada penelitian ini data yang digunakan dimodelkan dan diuji dengan ARIMA. Selanjutnya hasil dari data prediksi ARIMA akan dimodelkan menggunakan jaringan syaraf tiruan. Setelah mendapatkan hasil dari masing-masing metode maka akan dilakukan perbandingan dengan melihat error yang dihasilkan menggunakan MSE dan MAPE.

\section{HASIL DAN PEMBAHASAN}

Implementasi sistem ini terdiri dari tiga proses utama yaitu ARIMA, JST dan gabungan ARIMA dan JST. Tahap-tahap pemodelan ARIMA dalam penelitian ini meliputi:

1. Plot data asli.

2. Uji kestasioneran, Agar data stasioner maka dilakukan differencing dimulai dengan differencing.

3. Identifikasi model, dengan melihat plot ACF/PACF dapat ditentukan kira-kira model yang cocok. Penerapan model sementara dilakukan untuk menganalisa model manayang akan dipilih untuk prediksi.

4. Estimasi parameter, Dari beberapa pemodelan yang telah ditentukan pada tahap 3 didapatkan hasil MSE dan MAPE.

5. Diagnostik cek, pengidentifikasian untuk menentukan model mana yang paling cocok digunakan. 
6. Prediksi, langkah terakhir yang harus dilakukan adalah prediksi untuk beberapa periode ke depan.

Pemodelan ARIMA untuk kelompok tarif sosial hasil seperti pada Tabel 2 dimana yang dipilih sebagai model optimal untuk JST adalah model ARIMA $(1,1,2)$

Tabel 1. Perbandingan MSE dan MAPE kelompok tarif sosial

\begin{tabular}{|c|c|c|}
\hline Model & MSE & MAPE \\
\hline $3,1,2$ & 0.00839 & 0.0049 \\
\hline $1,1,1$ & 0.01235 & 0.00626 \\
\hline $2,1,2$ & 0.00714 & 0.00432 \\
\hline $1,1,2$ & 0.00675 & 0.00418 \\
\hline
\end{tabular}

Perhitungan MSE dan MAPE untuk kelompok tarif rumah tangga dapat dilihat pada Tabel 3. Dari Tabel 3 model yang dipilih adalah model ARIMA $(1,1,0)$.

Tabel 2. Perbandingan MSE dan MAPE kelompok tarif rumah tangga

\begin{tabular}{|l|c|l|}
\hline Model & \multicolumn{1}{|l|}{ MSE } & MAPE \\
\hline $3,1,2$ & 0.0101 & 0.00422 \\
\hline $1,1,1$ & 0.00604 & 0.00331 \\
\hline $2,1,2$ & 0.00873 & 0.00383 \\
\hline $1,1,2$ & 0.00675 & 0.00418 \\
\hline $1,1,0$ & 0.00529 & 0.00316 \\
\hline
\end{tabular}

Perhitungan MSE dan MAPE untuk kelompok tarif rumah tangga dapat dilihat pada Tabel 4. Dari Tabel model yang dipilih adalah model ARIMA $(1,1,2)$.

Tabel 3. Perbandingan MSE dan MAPE kelompok tarif bisnis

\begin{tabular}{|l|l|l|}
\hline Model & MSE & MAPE \\
\hline $3,1,2$ & 0.02013 & 0.00678 \\
\hline $1,1,1$ & 0.03579 & 0.00976 \\
\hline $2,1,2$ & 0.01698 & 0.00608 \\
\hline $1,1,2$ & 0.01704 & 0.00618 \\
\hline
\end{tabular}

Perbandingan MSE dan MAPE dari kelompok tarif industry. Dari Tabel model yang dipilih adalah model ARIMA $(2,1,2)$.

Tabel 4. Perbandingan MSE dan MAPE kelompok tarif industri

\begin{tabular}{|l|r|l|}
\hline Model & \multicolumn{1}{|l|}{ MSE } & \multicolumn{1}{l|}{ MAPE } \\
\hline $3,1,2$ & 0.01714 & 0.00659 \\
\hline $1,1,1$ & 0.03579 & 0.00976 \\
\hline $2,1,2$ & 0.013 & 0.00597 \\
\hline $1,1,2$ & 0.01336 & 0.00607 \\
\hline
\end{tabular}


Perbandingan MSE dan MAPE dari kelompok tarif industri dari Tabel model yang dipilih adalah model ARIMA $(1,1,0)$.

Tabel 5. Perbandingan MSE dan MAPE kelompok tarif pemerintah

\begin{tabular}{|l|l|r|}
\hline Model & \multicolumn{1}{|l|}{ MSE } & \multicolumn{1}{l|}{ MAPE } \\
\hline $3,1,2$ & 0.06209 & 0.0125 \\
\hline $1,1,1$ & 0.05435 & 0.01157 \\
\hline $2,1,2$ & 0.06215 & 0.01248 \\
\hline $1,1,2$ & 0.05369 & 0.01153 \\
\hline $1,1,0$ & 0.04156 & 0.01006 \\
\hline
\end{tabular}

Pelatihan pada jaringan syaraf tiruan dilakukan setelah data dibuat dengan data mana yang akan dilatih dalam hal ini data masing-masing kelompok tarif. Setelah dilakukan pelatihan maka data akan diuji. Dalam penelitian ini learning rate ditentukan sebesar 0.1 maksimum error 0.05, 6 neuron lapisan input, 20 neuron lapisan hidden, dan maksimum epoch 1000.

Tabel 6. Perbandingan MSE dan MAPE JST

\begin{tabular}{|l|l|l|}
\hline & MSE & MAPE \\
\hline Sosial & 0.41953 & 3.57052 \\
\hline Rumah Tangga & 0.34775 & 5.10571 \\
\hline Bisnis & 0.51039 & 16,44079 \\
\hline Industri & 0.13196 & 2.62063 \\
\hline Pemerintah & 0.45467 & 5.25051 \\
\hline
\end{tabular}

Tahap implementasi metode ARIMA-JST per kelompok tarif diperoleh dari model ARIMA. Input untuk jaringan syaraf tiruan diambil dari prediksi model ARIMA yang optimal dimana ketentuan input yaitu: 1) Input pada lag-1 $\left.\left(\mathrm{Y}_{\mathrm{t}-1}\right), 2\right)$ Input pada lag-1 $\left(\mathrm{Y}_{\mathrm{t}-1}\right)$, dan lag-2, 3) Input pada lag-1 $\left(\mathrm{Y}_{\mathrm{t}-1}\right)$, lag-2 $\left(\mathrm{Y}_{\mathrm{t}-2}\right), \operatorname{lag}-3\left(\mathrm{Y}_{\mathrm{t}-3}\right), \operatorname{lag}-4\left(\mathrm{Y}_{\mathrm{t}-4}\right), \operatorname{lag}-5\left(\mathrm{Y}_{\mathrm{t}-5}\right), \operatorname{lag}-6\left(\mathrm{Y}_{\mathrm{t}-6}\right)$.

Table 7. Perbandingan MSE dan MAPE masing-masing kelompok tarif

\begin{tabular}{|c|c|c|c|c|c|c|c|c|c|c|}
\hline \multirow{2}{*}{ Lag } & \multicolumn{2}{|c|}{ Sosial } & \multicolumn{2}{c|}{ Rumah Tangga } & \multicolumn{2}{c|}{ Bisnis } & \multicolumn{2}{c|}{ Industri } & \multicolumn{2}{c|}{ Pemerintah } \\
\cline { 2 - 12 } & MSE & MAPE & MSE & MAPE & MSE & MAPE & MSE & MAPE & MSE & MAPE \\
\hline \multirow{2}{*}{$1,2,3,4,5,6$} & 0.118 & 1.3054 & 0.1225 & 2.6037 & 0.0952 & 2.8868 & 0.0759 & 1.177 & 0.0748 & 1.3102 \\
\hline 1,2 & 0.0656 & 1.3093 & 0.1465 & 2.4717 & 0.095 & 3.2243 & 0.0789 & 1.0548 & 0.08 & 1.5955 \\
\hline 1 & 0.0534 & 1.4599 & 0.1829 & 2.5237 & 0.0968 & 3.3292 & 0.0812 & 1.2062 & 0.0808 & 1.6194 \\
\hline
\end{tabular}

Perbandingan MSE dan MAPE di atas menunjukkan berbagai macam hasil dari setiap lag yang menjadi input. Untuk kelompok tarif sosial MSE paling kecil dengan model JST $(1,20,1)$. Kelompok tarif rumah tangga model JST $(6,20,1)$, kelompok tarif bisnis $(2,20,1)$, kelompok tarif industri $(6,20,1)$ dan kelompok tarif pemerintah $(6,20,1)$. 
Table 8. Perbandingan ARIMA, JST dan Hibrid

\begin{tabular}{|l|l|r|l|r|}
\hline & & \multicolumn{3}{|c|}{ MSE } \\
\cline { 3 - 5 } Kelompok Tarif & Model ARIMA & ARIMA & JST & \multicolumn{1}{l|}{ Hibrid } \\
\hline Sosial & $1,1,2$ & 0.00675 & 0.41953 & 0.0534 \\
\hline Rumah Tangga & $1,1,0$ & 0.00529 & 0.34775 & 0.1225 \\
\hline Bisnis & $1,1,2$ & 0.01704 & 0.51039 & 0.095 \\
\hline Industri & $2,1,2$ & 0.013 & 0.13196 & 0.0759 \\
\hline Pemerintah & $1,1,0$ & 0.04156 & 0.45467 & 0.0748 \\
\hline
\end{tabular}

\section{KESIMPULAN}

1. Melihat hasil yang didapat dari perhitungan error MSE jaringan syaraf tiruan memiliki MSE yang paling besar. Sedangkan gabungan ARIMA dan JST MSE tidak berbeda jauh.

2. MSE terkecil dari kelompok tarif sosial 0.00675 , kelompok tarif rumah tangga 0.00529 , kelompok tarif bisnis 0.01704, kelompok tarif industri 0.013, dan kelompok tarif pemerintah 0.0748 .

3. Setiap error berbeda tergantung bentuk data.

4. Dalam penelitian ini yang diuji adalah untuk prediksi 6 periode ke depan.

\section{UCAPAN TERIMA KASIH}

Penulis mengucapkan terima kasih kepada pihak PLN wilayah Suluttenggo yang telah mengizinkan penulis melakukan penelitian di wilayah ini.

\section{DAFTAR PUSTAKA}

[1] Chang, P. C., Fan, C.Y. dan Hsieh, J. C., 2009. A Weighted Evolving Fuzzy Neural Network for Electricity Demand Forecasting. IEEE, pp.330-35.

[2] Li, X. dan Zhang, P., 2009. Medium-long Power Load Forecasting Based on Improved Grey BP Model. IEEE, pp.366-68.

[3] Munarsih, E., 2011. Penerapan Model ARIMA-Neural Network Hybrid untuk Peramalan Time Series. Tesis. Yokyakarta: Universitas Gadjah Mada.

[4] Wei, L. dan Zhen-gang, Z., 2009. Based On Time Sequence of ARIMA Model In the Application of Short-Term. In International Conference on Research Challenges in Computer Science., 2009. IEEE. 
[5] Rahayu, T.P., 2005. Sistem Peramalan Beban Listrik Menggunakan Jaringan Syaraf Tiruan. Tesis. Yogyakarta: Universitas Gadjah Mada.

[6] Faisal, F. dan Rizal, J., 2008. Penerapan Model Analisis Time Series Dalam Peramalan Pemakaian Kwh Listrik Untuk n-Bulan Ke depan Yang Optimal Di Kota. Jurnal Gradien, Vol.4 , pp. 323-327.

[7] Bunnoon, P., Chalermyanont, K. dan Limsakul, a.C., 2009. Mid Term Load Forecasting of the Country Using. IEEE, pp.924-28.

[8] Wei, L. dan Zhen-gang, Z., 2009. Based On Time Sequence of ARIMA Model In the Application of Short-Term. In International Conference on Research Challenges in Computer Science., pp.11-14

[9] Nugroho, B., 2011. Perbandingan Akurasi Peramalan Metode ARIMA dan GARCH Untuk Memprediksi IHSG Periode 1991-2011. Tesis. Yogyakarta: Universitas Gadjah Mada.

[10] Sudjana, 1976. Statistika untuk Ekonomi dan Niaga. Bandung: TARSITO.

[11] Fausett, L., 1994. Fundamentals of Neural Networks. Englewood Cliffs, New Jersey: Prentice-Hall, Inc. 